Original Research Paper

\title{
Mesenchymal Stem Cell Transplantation for Retinal Degenerations and Dystrophies: Present and Future
}

\author{
Emma Ghazaryan, Shurong Wang, Yan Zhang, Yuxi He and Guanfang Su \\ Eye Hospital, 2nd Teaching Hospital of Jilin University, Changchun, China
}

\author{
Article history \\ Received: 16-08-2014 \\ Revised: 28-11-2014 \\ Accepted: 30-11-2014 \\ Corresponding Author: \\ Guanfang Su, \\ Eye Hospital, 2nd Teaching \\ Hospital of Jilin University, \\ Changchun, China \\ Email: sugf2012@163.com
}

\begin{abstract}
Retinal degenerations are the main causes of irreversible blindness in developed countries. Up to date the main pathological mechanisms of these diseases are not fully understood and consequently there is no complete treatment option for those diseases. In this aspect stem cells have drawn attention of many researchers and health care professionals. Considering ethical issues, safety and facile isolation Mesenchymal Stem Cells (MSCs) are more preferable for practical use. They have been used for several preclinical and clinical trials. In general the results were promising, however broader practical use should be preceded by resolving many problems and questions. In this review we will describe mesenchymal stem cells, especially those derived from Bone-Marrow (BMSC), their main features, privilege, mechanisms of action and their potential use for the treatment of retinal degenerations. We will also discuss the results of several pre-clinical and clinical trials.
\end{abstract}

Keywords: Retinal Degenerations, Stem Cell, Mesenchymal Stem Cells, Transplantation, Preclinical and Clinical Trials

\section{Introduction}

Retinal degenerations, which are mainly due to the genetic defects, diabetes, aging and environmental factors, are the main causes of irreversible blindness in developed countries. The final result of all types of retinal degenerations and dystrophies is the loss of photoreceptor cells, which leads to irreversible vision loss. Generally, all types of retinal degenerations progress through similar main mechanisms, with differences at the first step of the pathologic pathway. They all progress to the apoptosis of photoreceptors, total ablation of the Outer Nuclear Layer (ONL) of the retina and consequent neural remodeling of the inner neural retina (Marc et al., 2003). In the meanwhile, some types of retinal cells can escape apoptosis and preserve their main functional ability as latent cells, which made possible restoration of lost vision with electrical implants (Da Cruz et al., 2013). This gives hope that transplantation of new photoreceptors will reactivate retina and restore vision.

\section{Stem Cells}

Stem cells are undifferentiated cells with the ability of self-renewal and differentiation into more specialized cells.

The ideas about existence of stem cells came first after bombing in Hiroshima and Nagasaki in $1940 \mathrm{~s}$.
Those who died over a prolonged period from lower doses of radiation had compromised hematopoietic systems that could not regenerate either sufficient white blood cells to protect against otherwise nonpathogenic infections or enough platelets to clot their blood. Later, it was demonstrated that mice that were given doses of whole body X-irradiation developed the same radiation syndromes; at the minimal lethal dose, the mice died from hematopoietic failure approximately two weeks after radiation exposure. Soon thereafter, using inbred strains of mice, scientists showed that whole-bodyirradiated mice could be rescued from otherwise fatal hematopoietic failure by injection of suspensions of cells from blood-forming organs such as the bone marrow. In 1961 the hematopoietic stem cells were isolated from bone marrow and since then are used in clinical practice for hematologic diseases. Friedenstein et al. (1976) described mesenchimal stem cells and called them fibroblast precursors. Later, Thomson et al. (1998) discovered embryonic stem cell, Yamanaka and Takahashi (2006) showed that they were able to transform typical fibroblast from adult skin into pluripotent stem cell and they named it induced Pluripotent Stem cell (iPS).

Now three main types of stem cells are in use: Embryonic Stem Cells (ESC), Adult stem cells, Induced Pluripotent Stem cells (iPS). IPS and ESC grow faster, are being pluripotent and can differentiate 
into any kind of cell upon appropriate stimulation, but they have practical problems, halting their clinical use. They raise ethical issues and have high risks of immune rejection and tumorogenesis. In contrast to ESC and iPS, MSCs are more suitable for stem cell therapy,because of facile isolation and invitroculture,prolonged self-renewal ability, autotrasplantation, low risk of tumor formation (Caplan, 2009) and a lack of ethical issues. There have been many studies showing that these cells are safe and have good plasticity, without producing tumors (Herzog et al., 2003; Phinney et al., 2006; Zhang and Alexanian, 2014). As such, they are preferred for transplantation therapy.

Mesenchymal stem cells can be isolated from different organs and tissues: Bone-marrow, adipose tissue, teeth pulp and also amniotic fluid, umbilical cord, placenta, etc (Erices et al., 2000; Prusa et al., 2003). The most researched and used are Bonemarrow derived Mesenchymal Stem Cells (BMSC). Generally BMSC are found in bone-marrow niche where they make trophic basis for hematopoietic cells (Bianco et al., 2001). Several researchers suggest, that these BMSC are located around the vessels in the stroma of BM and they play rolesaspericytes, that can be mobilized from BM with special stimulus and migrate to the site of injury to perform their cellular functions (Wu et al., 2007; Caplan, 2008). The ratio of BMSC is decreasing with age: For newborns it's 1:104 of nucleated cells of BM; for teens it goes down to $1: 105$ and for adults it goes further down to $1: 106$ or less (Caplan, 2009). This is consistent with that regeneration is faster and more complete in children than in adults and degenerative diseases start to manifest mainly in aged people.

\section{Bone Marrow-Derived Mesenchymal Stem Cells}

Bone marrow-derived Mesenchymal Stem Cells (BMSCs) are described with several features: They are isolated from bone-marrow, adherent to the bottom of plastic culture dishes, obtain spindle shape like fibroblasts and express a combination of cell surface markers (CD105, CD90, CD29, etc and negative for CD31, CD45, CD11b, etc). Under appropriate conditions, they can give rise to muscles, adipose tissue or bone cells. Although above characteristics are well among scientists, more detailed characterizations show that MSC from different species, organs and tissues, despite having many common features, have differences in the expression of cell surface markers, cytokine production and growth factors production, in addition tochanging certain characteristics after ex-vivo culturing (Javazon et al., 2004; Martins et al., 2009; Bayati et al., 2013).
MSC are able to recover injured tissues and organs through following mechanism: Cellular transdifferentiation and cell replacement, paracrine trophic function (Crisostomo et al., 2008). They also can be used as non-viral, safe, prolonged acting vehicles for gene therapy or drug introduction (Arnhold et al., 2006; Park et al., 2012).

The beneficial action of transplanted MSCs is suggested to be due to the production of trophic factors (Uccelli et al., 2011), however the ability of integration and differentiation is still questionable (Harris et al., 2006; Xu and Liu, 2008).

MSC are preferred for auototransplantation. Recently researches showed that BMSC don't express MHC class II antigens, co-stimulatory molecules CD80, CD 84 or CD40 and only express low quantity of MHC class I antigens, so they can be invisible for recipient immune system. This makes MSCs universal also forallo-and even xeno-transplantations (Chiou et al., 2005). It was also shown that MSC itself suppresses immune system by suppressing T-cell, Bcell and NK activity (Tse et al., 2003; Ribeiro et al., 2013). This function was even used for clinical experiments, Graft Versus Host Disease treatment, etc (Ning et al., 2008; Puymirat et al., 2009; Baron et al., 2010). MSC derived from adipose tissue, umbilical cord, amniotic fluid and bone-marrow showed generally similar characteristics, so cells for transplantations can be obtained from medical wastes (liposuction, placenta, Umbilical Cord (UC), amniotic fluid after delivery) and used safely for allotransplantations (Oh et al., 2011; Tejaswi et al., 2013; Ribeiro et al., 2013).

\section{MSCs in Retinal Degenerations}

Retinitis Pigmentosa (RP) and Age-Related Macular Degeneration (AMD) are the most common cases of retinal degenerations. Many scientific groups focused on these diseases, aiming at revealing pathological mechanisms and final treatment options for them. They also serve as main models for stem cell transplantation for retinal degenerations.

\section{Retinitis Pigmentosa}

Retinitis Pigmentosa is described by the primary or secondary loss of photoreceptors due to gene abnormalities. Its rate is about 1:3000-1:7000. Usually, RP starts with the loss of rods and followed by the loss of cones. RPE cells detach from Bruch's membrane, migrate to inner retina and associate with abnormal vessels. Extracellular matrix deposits between RPE cells and endothelial cells of the vessels and closely resembles Bruch's membrane in situ. Further disease progress to the formation of bone 
spicules (Ehinger, 2000). RP manifests in early teens with poor night vision (nyctalopia), prolonged dark adaptation and gradually progresses to tunnel vision and total blindness by the age of 40-50 years. Nevertheless, some patients preserve their central vision (preservation of cones) even with lost visual fields. Nearly 180 gene mutations are known for RP, but they represent just $15 \%$ of phenotypic appearance of the disease. This makes gene engineering therapy quite difficult or impossible for most patients. No effective treatment is currently available for patients with RP. Under these circumstances, stem cell therapy may be a hope to those patients.

Different groups showed that with special growth factors or mediums they were able to differentiate BMSC into neural progenitor cells and further to retinal cells (Kicic et al., 2003; Yang et al., 2010; Zhang and Alexanian, 2014). This lead to experiments on animals and recently to several clinical trials for RP treatment.

For the retina transplantation there are three possible routes: Intravitreal injection, subretinal injection and intravenous injection. The first two are local and have their benefits and drawbacks: Particularly subretinal injection provides direct contact between BMSC, RPE layer and photoreceptors, but it is difficult to perform and risky.During degeneration Muller glial seal occupies the area and may prevent cell implantation and incorporation (Kicic et al., 2003; Arnhold et al., 2007; Inoue et al., 2007; Gong et al., 2008). Intravitreal injection is easy to perform, less risky, but it doesn't provide close contact with retinal and transplanted cells (Castanheira et al., 2008; Hill et al., 2009; Li et al., 2009; Wang et al., 2010a; Tsuruma et al., 2014). In addition Internal Limiting Membrane (ILM) may prevent cells from integration. It will be interesting to see whether intravenous injection can be a successful route of the cell therapy for the retina. Many works showed that after IV injection MSCs migrated and localized in injured liver, heart, brain and retina, but in this case more cells were required for injection $(\mathrm{Xu}$ et al., 2007; Jackson et al., 2010; Wang et al., 2010b). In fact BMSC express main chemokine receptors (CC, $\mathrm{CXC}, \mathrm{C}$ and $\mathrm{CX} 3 \mathrm{C}$ ) and can be attracted by their ligands, especially SDF-1 and IL-8 (Ringe et al., 2007; Shi et al., 2007). It is known that production of SDF-1 is augmented after injuries, so BMSC migrate exactly to the injured tissue, remaining in very small quantities in other organs. But in all preclinical trials animal models with only one disease were used. Thisis not similar to human body, especially in diabetic or aged people, with many problems within body. In this case it's not clear, whether stem cells will be able to migrate to relatively small retina? Although many beneficial effects from BMSC transplantation have been shown, it's not clear whether BMSC can be used to treat diseases at multiple sites of the body with intravenous injection.

After choosing the best route the second problem is when BMSC should be transplanted? For ESC even final stages of disease are eligible for transplantation with normal transdifferentiation and functional recovery (Singh et al., 2013), unfortunately for BMSC transplantation results are not that promising. The problem is due to remodeled retina, Muller glial seal and not permissive extracellular matrix for transplanted cells survival. This was shown in the work of Johnson and coworkers, who showed that after peeling of ILM with Muller cells neurits better integration and transdifferentiation rates were observed (Johnson et al., 2009). In animal models, highest levels of integration were observed in the models of retina laser injuries, which disrupt ILM (Castanheira et al., 2008; Wang et al., 2010a). Also higher integration and transdifferentiation rates were reported, if treatment was started within 24-48 h after injury.

However, the published articles showed rescue of anatomical structure and function of the retina compared to control untreated groups, but none found the toxic reaction or tumor formation after an observational period of over $230 \mathrm{~d}$. This made the recruitment of clinical trials with MSC transplantation possible. Several groups have already reported onthe safety and feasibility of an intravitreal injection of stem cell (Jonas et al., 2010; Siqueira et al., 2011; Siqueira et al., 2013).

Several pre-clinical and clinical trials are summarized in Table 1.

But before wide use of stem cell transplantation in clinical practice many questions should be answered, particularly:

- How many cells should be transplanted and from which passage of cells

- Is it necessary to primarily induce cells in-vitro to specified lines or should they be induced with in-vivo

- In which stage of disease it is more effective and safer to transplant

- Which is the best transplantation route

\section{Age-Related Macular Degeneration}

Age-Related Macular Degeneration is a multifactorial disease caused by genetic predisposition and environmental factors, occurring with a rate of $18 \%$ at the age of $50-60$ and over $30 \%$ at the age of 70 (Friedman et al., 2004). 
Table 1. Summarized table of pre-clinical and clinical trials

Author and the year

of publication

Kicic et al.

(2003)

Otani et al.

(2004)

Arnhold et al.

(2006)

Harris et al.

(2006)

Arnhold et al.

(2007)

Inoue et al.

(2007)

Castanheira et al.

(2008)

Sasahara et al.

(2008)

Gong et al.

(2008)

Li et al.

(2009)

Hill et al.

(2009)

Wang et al.

(2010b)

Zhang and Wang

(2010)

Wang et al.

(2010a)

Chung et al.

(2011)

Lee et al.

(2011)

Park et al.

(2012)

Huang et al.

(2013)

Guan et al.

(2013)

Tsuruma et al. (2014)

Tzameret et al.

(2014)

Siqueira (2010)

Janssen Research

and Development,

LLC (2010)

Siqueira et al. (2011;

Siqueria (2011)

Rubens Camargo

Siqueira (2012);

Atchaneeyasakul et al.

(2012;

Atchaneeyasakul, 2012)

UC (2012)
Type of study Disease model

Animal model Retinal degeneration

in RCS rats

Animal model Retinal degenerations

in or rdland rd10 mice

Animal model

Retinal degeneration

in $\mathrm{RCS}$ rats

Animal model Physical or chemical

damage of retina

Animal model Retina of the rhodopsin

knockout mouse

Animal model Retinal degeneration

in RCS rats

Animal model Laser-injured retina

Animal model

Animal model of

retinitis pigmentosa

Animal model

Sodium-iodate induced

retinal degeneration

Animal model

Retina injured by

ischemia-reperfusion

Animal model

Degenerating neonatal rat

retina following intracranial

optic tract lesion

Animal model Laser-injured retina

Animal model Light-damaged retina

Animal model Retinal degeneration

in $\mathrm{RCS}$ rats

Animal model

Retinotomies with

Nd: YAG laser

Animal model Developing mouse eye

Animal model Axotomized retina

Animal model Light-injured retina

Animal model

Sodium-iodateinduced

retinal degeneration

Animal model Light-injured retina

Animal model Retinal degeneration

in $\mathrm{RCS}$ rats

Clinical trial

Phase 1

Clinical trial

Phase1/2a

Clinical trial

Phase $1 / 2$

Clinical trial

Phase 2

Clinical trial

Phase 1

Retinitis Pigmentosa

Age-related Macular

Degeneration

Advanced Age-Related

Macular Degeneration

Retinitis Pigmentosa

Retinitis Pigmentosa

Clinical trial

Phase 1
Dry Age-related

Macular Degeneration

Diabetic retinopathy

Retina vein occlusion
Injection route Cells type

Subretinal Bone marrow-derived

mesenchymal stem cells

Intravitreal bone marrow-derived lieangenegative hematopoietic stem cells

Subretinal Adenovirally transduced for

PEDF expression BMSCs

Endogeneoushematopoetic stem and progenitor cells

Subretinal

Bone marrow-derived mesenchymal stem cells

Bone marrow-derived

mesenchymal stem cells

Bone marrow-derived

mesenchymal stem cells

Endogenous BM-derived microglia

Subretinal

Bone marrow-derived mesenchymal stem cells

Intravitreal

Bone marrow-derived mesenchymal stem cells

Intravitreal

Umbilical cord blood-derived mesenchymal stem cells

Intravitreal

Subretinal

quantum dot-labelled bone marrow-derived stem cells

Bone marrow-derived mesenchymal stem cells

Systemically- Bone marrow-derived

intravenous mesenchymal stem cells

Systemically- Bone marrow-derived

intravenous mesenchymal stem cells

Intraocular

Bone marrow-derived mesenchymal stem cells

Subretinal Transduced BMSCs for

BDNF expression

Subretinal

Normal MSC and

CX3CL1-expressing MSC

Subretinal

Normal MSC or erythropoietin gene modified MSC

Intravitreal

Adipose-derived stem cells

Subretinal

thin layer

Intravitreal

Subretinal

Human bone marrow-derived mesenchymal stem cells

Bone marrow-derived mesenchymal stem cells CNTO 2476 (Human umbilical tissue-derived cells)

Intravitreal

Bone marrow-derived mesenchymal stem cells

Intravitreal

Bone marrow-derived

Intravitreal

mesenchymal stem cells

Bone marrow-derived

mesenchymal stem cells

Intravitreal

CD34+ bone marrow stem cells 
Table 1. Continue

Retinitis pigmentosa

Phase $1 / 2$

RASF (2013) Clinical trial

Retinitis pigmentosa
Retinitis pigmentosa
Retinal disease macular
degeneration hereditary
retinal dystrophy
optic nerve disease
glaucoma

Retinitis pigmentosa
Retinitis pigmentosa

Retinal disease macular degeneration hereditary glaucoma

$\begin{array}{ll}- & \begin{array}{l}\text { Bone marrow-derived } \\ \text { mesenchymal stem cells }\end{array} \\ \text { Retrobulbar } & \begin{array}{l}\text { Bone marrow-derived } \\ \text { mesenchymal stem cells }\end{array} \\ \text { Subtenon } & \\ \text { Intravenous } & \\ \text { Intravitreal } & \\ \text { Intraocular } & \end{array}$

It's the leading cause of irreversible blindness in the western countries and the rate is continuously going up because of the rapid increasing of averaged age (Kolar, 2010). Generally, AMD is classified as dry or nonexudative AMD and wet or neovascular AMD, according to the presence or the absence of Neovascularization (NV). Two late forms of the disease (GA, CNV) are so different in their manifestation and in treatment options, that it is appropriate to consider them as two different diseases and it's also not clear, what is the switch point between GA and CNV, or in another word, what determines the disease to progress into GA rather than $\mathrm{CNV}$ or vice versa? There are several treatment strategies for AMD (AREDS formulations, laser photocoagulation, photodynamic therapy, antiVEGF drugs, etc.), but none of them is able to stop the progression, not to mention to cure the disease. So for those patients stem cell therapy is believed to be the main choice, however, it is quite different for two forms of disease: In GA use of stem cells is quite similar to that of RP, but in neovascularizations (wet AMD, DR) mechanisms are more complicated and controversial. The main character of wet AMD is neovascularization. Neovascularization is connected with impaired proportion of pro-and anti-angiogenetic factors, with overexpression of the pro-ones, especially VEGF. MSCs produce VEGF in big quantities, which contribute to angiogenesis, so in eyes, stem cells may lead to neovascularization and have pathological effects. Supportively, many published works show that endogenous stem cells (especially Lin-HSC, EPC) participate in new vessel formation. Most studies used mice models with bone-marrow reconstituted by bonemarrow-derived stem cells from the Green Fluorescent Protein (GFP) transgenic mice and CNV was induced by laser spots (Espinosa-Heidmann et al., 2003; Sengupta et al., 2003; Takahashi et al., 2004; Tomita et al., 2004; Espinosa-Heidmann et al., 2005; Sengupta et al., 2005; Lecomte et al., 2011). Some studies showed that nearly $50 \%$ of cells in the new vessels were GFP positive, indicating they arise from bone-marrow. Hou et al. (2010) used external BMSC and showed their incorporation in new vessels without significant increase in CNV size. What is more important is that they used induced cells to produce Pigmented Epithelium-Derived Factor (PEDF), a strong antiangiogenic factor. Then they observed a decrease in CNV formation and vessels surroundedby RPE cells, which restricts neovascularization. They proposed to use stem cells only as a safe, prolonged source of anti-angiogenic factors (Hou et al., 2010). Later, blood examination from patients with active CNV showed higher level of BM derived stem cells in peripheral blood, but with low functional ability: There is no significant difference in the CFU-EC between patients with $\mathrm{CNV}$ and the control group; in case of bilateral CNV the levels of CFU-EC andSDF-1were significantly decreased (Yodoi et al., 2007; Machalinska et al., 2011).

It seems that BM derived stem cells don't contributeto new vessel formation, rather, they contribute tovessel maturation and regulate growth. Endogenous quantity of BMSCs is not enough and they are not functionally active, so they are not able to maturatenewvessels. Consistently, research of Chung et al. (2011) shows that after laser injury in non irradiated mice, injection of extra bone marrow stemcells contribute to resolution of retinal detachment without proliferative component (Chung et al., 2011). In the regards, further experiments are needed to understand the roles of transplanted MSCs in CNV formation.

\section{Conclusion}

Being the leading causes of blindness in the western countries, retinal degenerations don't have a definitive treatment option, which is a significant problem for both the patient and the clinicians. In the last 30 years research was focused on stem cells and their possible application in the treatment of retinal degenerative disease.

Despite the extensive research done in the past three decades and many pre-clinical and several clinical trials conducted, many questions and problems are still not solved, preventing wide application of stem cells in clinical practice. But significant progress has been made toward both prevention and treatment of retinal degenerations and we envision the clinical application of stem cells will open a new era of treating those eye diseases. 


\section{Conflict of Interest}

Authors certify that there is no conflict of interest with any financial organization regarding the material discussed in the manuscript.

\section{Acknowledgement}

Researchers want to thank Anushavan Karapetyan and Liu Xin for their comments and assistance during paper writing.

This study was supported by the NSFC Fund, Jilin Province Science and Technology Agency fund. The funders had no role in study design, data collection and analysis, decision to publish, or preparation of the manuscript.

\section{Author's Contribution}

Emma Ghazaryan and Shurong Wang: Conception and design, data collection and manuscript writing.

Yan Zhang: Conception and data collection.

Yuxi He: Data collection

Guanfang Su: Conception, revision and final approval of the version.

\section{Ethics}

All authors read and approved the final version and are responsible for any ethical issue that may arise after the publication of this manuscript.

\section{References}

Arnhold, S., P. Heiduschka, H. Klein, Y. Absenger and U. Schraermeyer et al., 2006. Adenovirally transduced bone marrow stromal cells differentiate into pigment epithelial cells and induce rescue effects in RCS rats. Invest. Ophthalmol. Vis. Sci., 47: 4121-4129.

DOI: $10.1167 /$ iovs.04-1501

Arnhold, S., Y. Absenger, H. Klein, K. Addicks and U. Schraermeyer, 2007. Transplantation of bone marrow-derived mesenchymal stem cells rescue photoreceptor cells in the dystrophic retina of the rhodopsin knockout mouse. Graefes Arch. Clin. Exp. Ophthalmol., 245: 414-422.

DOI: $10.1007 / \mathrm{s} 00417-006-0382-7$

Atchaneeyasakul, 2012. Feasibility and safety of adult human bone marrow-derived mesenchymal stem cells by intravitreal injection in patients with retinitis pigmentosa. ClinicalTrial.gov.

Atchaneeyasakul, L.O., A. Trinavarat, P. Chiewvit, J. Buaboonnam and K. Sanpakit, 2012. Selective ophthalmic arterial infusion of chemotherapeutic drugs for recurrent retinoblastoma. J. Pediatric Hematol. Oncol., 34: 218-218.

DOI: 10.1097/MPH.0b013e318253f09e
Baron, F., C. Lechanteur, E. Willems, F. Bruck and Y. Beguin et al., 2010. Cotransplantation of mesenchymal stem cells might prevent death from Graft-Versus-Host Disease (GVHD) without abrogating graft-versus-tumor effects after HLAmismatched allogeneic transplantation following nonmyeloablative conditioning. Biol. Blood Marrow Transplant, 16: 838-847. DOI: $10.1016 /$ j.bbmt.2010.01.011

Bayati, V., M. Hashemitabar, R. Gazor, R. Nejatbakhsh and D. Bijannejad, 2013. Expression of surface markers and myogenic potential of rat bone marrow-and adipose-derived stem cells: A comparative study. Anat. Cell Biol., 46: 113-121. DOI: $10.5115 / \mathrm{acb} .2013 .46 .2 .113$

Bianco, P., M. Riminucci, S. Gronthos and P.G. Robey, 2001. Bone marrow stromal stem cells: Nature, biology and potential applications. Stem Cells, 19: 180-192.

DOI: $10.1634 /$ stemcells. 19-3-180

Caplan, A.I., 2008. All MSCs are pericytes. Cell Stem Cell, 3: 229-230. DOI: $10.1016 /$ j.stem.2008.08.008

Caplan, A.I., 2009. Why are MSCs therapeutic? New data: New insight. J. Pathol., 217: 318-324. DOI: 10.1002/path.2469

Castanheira, P., L. Torquetti, M. B. Nehemy and A.M. Goes, 2008. Retinal incorporation and differentiation of mesenchymal stem cells intravitreally injected in the injured retina of rats. Arq. Bras Oftalmol., 71: 644-650. DOI: $10.1590 / \mathrm{S} 000427492008000500007$

Chiou, S.H., C.L. Kao, C.H. Peng, S.J. Chen and C.H. Lee et al., 2005. A novel in vitro retinal differentiation model by co-culturing adult human bone marrow stem cells with retinal pigmented epithelium cells. Biochem. Biophys. Res. Commun., 326: 578-585.

DOI: $10.1016 /$ j.bbrc.2004.11.061

Chung, J.K., T.K. Park, Y.H. Ohn, S.K. Park and D.S. Hong et al., 2011. Modulation of retinal wound healing by systemically administered bone marrow-derived mesenchymal stem cells. Korean J. Ophthalmol., 25: 268-274. DOI: $10.3341 / \mathrm{kjo} .2011 .25 .4 .268$

Crisostomo, P.R., T.A. Markel, Y. Wang and D.R. Meldrum, 2008. Surgically relevant aspects of stem cell paracrine effects. Surgery, 143: 577581. DOI: 10.1016/j.surg.2007.10.015

Da Cruz, L., B.F. Coley, J. Dorn, F. Merlini and I.I.S.G. Argus et al., 2013. The Argus II epiretinal prosthesis system allows letter and word reading and long-term function in patients with profound vision loss. Br. J. Ophthalmol., 97: 632-636.

DOI: 10.1136/bjophthalmol-2012-301525 
Ehinger, B., 2000. Tapetoretinal degenerations: Experiences, experiments and expectations. Acta Ophthalmol. Scand, 78: 244-255. DOI: 10.1034/j.1600-0420.2000.078003244.x

Erices, A., P. Conget and J.J. Minguell, 2000. Mesenchymal progenitor cells in human umbilical cord blood. Br. J. Haematol., 109: 235-242. DOI: $10.1046 /$ j.1365-2141.2000.01986.x

Espinosa-Heidmann, D.G., A. Caicedo, E.P. Hernandez, K.G. Csaky and S.W. Cousins, 2003. Bone marrow-derived progenitor cells contribute to experimental choroidal neovascularisation. Invest. Ophthalmol. Vis. Sci., 44: 4914-4919. DOI: $10.1167 /$ iovs.03-0371

Espinosa-Heidmann, D.G., M.A. Reinoso, Y. Pina, K.G. Csaky and S.W. Cousins et al., 2005. Quantitative enumeration of vascular smooth muscle cells and endothelial cells derived from bone marrow precursors in experimental choroidal neovascularisation. Exp. Eye Res., 80: 369-378. DOI: 10.1016/j.exer.2004.10.005

Friedenstein, A.J., J.F. Gorskaja and N.N. Kulagina, 1976. Fibroblast precursors in normal and irradiated mouse hematopoietic organs. Exp. Hematol., 4: 26774. PMID: 976387.

Friedman, D.S., B.J. O'Colmain, B. Munoz, S.C. Tomany and G. Eye et al. 2004. Prevalence of agerelated macular degeneration in the United States. Arch. Ophthalmol., 122: 564-572. DOI: 10.1001/archopht.122.4.564

Gong, L., Q. Wu, B. Song, B. Lu and Y. Zhang, 2008. Differentiation of rat mesenchymal stem cells transplanted into the subretinal space of sodium iodate-injected rats. Clin. Exp. Ophthalmol., 36: 666-671. DOI: 10.1111/j.1442-9071.2008.01857.x

Guan, Y., L. Cui, Z. Qu, L. Lu and G.T. Xu et al., 2013. Subretinal transplantation of rat MSCs and erythropoietin gene modified rat MSCs for protecting and rescuing degenerative retina in rats. Curr. Mol. Med., 13: 1419-1431. DOI: $10.2174 / 15665240113139990071$

Harris, J.R., G.A. Brown, M. Jorgensen, S. Kaushal and E.W. Scott et al., 2006. Bone marrow-derived cells home to and regenerate retinal pigment epithelium after injury. Invest. Ophthalmol. Vis. Sci., 47: 21082113. DOI: $10.1167 /$ iovs.05-0928

Herzog, E.L., L. Chai and D.S. Krause, 2003. Plasticity of marrow-derived stem cells. Blood, 102: 34833493. DOI: 10.1182/blood-2003-05-1664

Hill, A.J., I. Zwart, H.H. Tam, J. Chan and R. Navarrete et al., 2009. Human umbilical cord blood-derived mesenchymal stem cells do not differentiate into neural cell types or integrate into the retina after intravitreal grafting in neonatal rats. Stem cells Dev., 18: 399-409.

DOI: $10.1089 / \mathrm{scd} .2008 .0084$
Hou, H.Y., H.L. Liang, Y.S. Wang, Z.X. Zhang and Y. Cai et al., 2010. A therapeutic strategy for choroidal neovascularization based on recruitment of mesenchymal stem cells to the sites of lesions. Mol. Ther., 18: 1837-1845.

DOI: $10.1038 / \mathrm{mt} .2010 .144$.

Huang, L., W. Xu and G. Xu, 2013. Transplantation of CX3CL1-expressing mesenchymal stem cells provides neuroprotective and immunomodulatory effects in a rat model of retinal degeneration. Ocul. Immunol. Inflamm., 21: 276-285. DOI: $10.3109 / 09273948.2013 .791925$

Inoue, Y., A. Iriyama, S. Ueno, H. Takahashi and Y. Yanagi et al., 2007. Subretinal transplantation of bone marrow mesenchymal stem cells delays retinal degeneration in the RCS rat model of retinal degeneration. Exp. Eye Res., 85: 234-241. DOI: 10.1016/j.exer.2007.04.007

Jackson, J.S., J.P. Golding, C. Chapon, W.A. Jones and K.K. Bhakoo, 2010. Homing of stem cells to sites of inflammatory brain injury after intracerebral and intravenous administration: A longitudinal imaging study. Stem Cell Res. Ther., 1: 17-17. DOI: $10.1186 /$ scrt 17

Jamadar, 2013b. Clinical study to evaluate safety and efficacy of BMMNC in retinitis pigmentosa. ClinicalTrial.gov.

Jamadar, S., 2013a. Safety and Efficacy of BMMNC in Patients With Chronic Renal Failure. Chaitanya Hospital, Pune.

Janssen Research and Development, LLC, 2010. A safety study of CNTO 2476 in patients with agerelated macular degeneration. ClininicalTrials.gov.

Javazon, E.H., K.J. Beggs and A.W. Flake, 2004. Mesenchymal stem cells: Paradoxes of passaging. Exp. Hematol., 32: 414-425.

DOI: $10.1016 /$ j.exphem.2004.02.004

Johnson, T.V., N.D. Bull and K.R. Martin, 2009. Transplantation prospects for the inner retina. Eye London Eng., 23: 1980-1984.

DOI: 10.1038 /eye.2008.376

Jonas, J.B., M. Witzens-Harig, L. Arseniev and A.D. Ho, 2010. Intravitreal autologous bone-marrow-derived mononuclear cell transplantation. Acta Ophthalmol., 88: 131-132.

DOI: 10.1111/j.1600-0420.2007.00987.x

Kicic, A., W.Y. Shen, A.S. Wilson, I.J. Constable, T. Robertson and P.E. Rakoczy, 2003. Differentiation of marrow stromal cells into photoreceptors in the rat eye. J. Neurosc. Official J. Society Neurosci., 23: 7742-7749.

Kolar, P., 2010. Epidemiology of the age-related macular degeneration. Cesk. Slov. Oftalmol., 66: 127-130. DOI: 10.1016/j.ajo.2003.11.069 
Lecomte, J., K. Louis, B. Detry, S. Blacher and A. Noel et al., 2011. Bone marrow-derived mesenchymal cells and MMP13 contribute to experimental choroidal neovascularisation. Cellular Molecular Life Sci., 68: 677-686. DOI: 10.1007/s00018-010-0476-6

Lee, E.S., S.H. Yu, Y.J. Jang, D.Y. Hwang and C.J. Jeon, 2011. Transplantation of bone marrow-derived mesenchymal stem cells into the developing mouse eye. Acta Histochemica et Cytochemica, 44: 213221. DOI: $10.1267 /$ ahc. 11009

Li, N., X.R. Li and J.Q. Yuan, 2009. Effects of bonemarrow mesenchymal stem cells transplanted into vitreous cavity of rat injured by ischemia/reperfusion. Graefes Arch. Clin. Exp. Ophthalmol., 247: 503-514. DOI: $10.1007 / \mathrm{s} 00417-008-1009-y$

Machalinska, A., P. Klos, K. Safranow, V. Dziedziejko and B. Machalinski, 2011. Neural stem/progenitor cells circulating in peripheral blood of patients with neovascular form of AMD: A novel view on pathophysiology. Graefes Arch, Clin. Exp. Ophthalmol., 249: 1785-1794.

DOI: $10.1007 / \mathrm{s} 00417-011-1767-9$

Marc, R.E., B.W. Jones, C.B. Watt and E. Strettoi, 2003. Neural remodeling in retinal degeneration. Prog. Retin. Eye Res., 22: 607-655. DOI: $10.1016 / \mathrm{S} 1350-9462(03) 00039-9$

Martins, A.A., A. Paiva, J.M. Morgado, A. Gomes and M.L. Pais, 2009. Quantification and immunophenotypic characterization of bone marrow and umbilical cord blood mesenchymal stem cells by multicolor flow cytometry. Transplant. Proc., 41: 943-946.

DOI: 10.1016/j.transproceed.2009.01.059

Ning, H., F. Yang, M. Jiang, L. Hu and H. Chen et al., 2008. The correlation between cotransplantation of mesenchymal stem cells and higher recurrence rate in hematologic malignancy patients: Outcome of a pilot clinical study. Leukemia, 22: 593-599. DOI: $10.1038 /$ sj.leu. 2405090

Oh, J.S., K.N. Kim, S.S. An, W.A. Pennant and Y. Ha et al., 2011. Cotransplantation of mouse neural stem cells (mNSCs) with adipose tissue-derived mesenchymal stem cells improves mNSC survival in a rat spinal cord injury model. Cell Transplant., 20: 837-849. DOI: $10.3727 / 096368910 X 539083$

Otani, A., M.I. Dorrell, K. Kinder, S.K. Moreno and M. Friedlander et al., 2004. Rescue of retinal degeneration by intravitreally injected adult bone marrow-derived lineage-negative hematopoietic stem cells. J. Clin. Invest., 114: 765-774. DOI: $10.1172 / \mathrm{JCI} 21686$

Park, H.Y., J.H. Kim, H. Sun Kim and C.K. Park, 2012. Stem cell-based delivery of brain-derived neurotrophic factor gene in the rat retina. Brain Res., 1469: 10-23. DOI: 10.1016/j.brainres.2012.06.006
Phinney, D.G., K. Hill, C. Michelson, M. DuTreil and E. Bayly et al., 2006. Biological activities encoded by the murine mesenchymal stem cell transcriptome provide a basis for their developmental potential and broad therapeutic efficacy. Stem Cells, 24: 186-198. DOI: 10.1634/stemcells.2004-0236

Prusa, A.R., E. Marton, M. Rosner, G. Bernaschek and M. Hengstschlager, 2003. Oct-4-expressing cells in human amniotic fluid: A new source for stem cell research. Hum. Reprod., 18: 1489-1493. DOI: $10.1093 /$ humrep/deg279

Puymirat, J.,R. Pelletier, F. Hamela, D. Beaulieua and L. Patrya et al., 2009. Absence of a differentiation defect in muscle satellite cells from DM2 patients. Neurobiol. Dis., 36: 181-190. DOI: $10.1016 /$ j.nbd.2009.07.009

RASF, 2013. Stem cell ophthalmology treatment study (SCOTS). ClinicalTrial.gov.

Ribeiro, A., P. Laranjeira, S. Mendes, I. Velada and A. Paiva et al., 2013. Mesenchymal stem cells from umbilical cord matrix, adipose tissue and bone marrow exhibit different capability to suppress peripheral blood $\mathrm{B}$, natural killer and $\mathrm{T}$ cells. Stem Cell Res. Ther., 4: 125-125.

DOI: $10.1186 /$ scrt336

Ringe, J., S. Strassburg, K. Neumann, M. Endres and M. Sittinger et al., 2007. Towards in situ tissue repair: Human mesenchymal stem cells express chemokine receptors CXCR1, CXCR2 and CCR2 and migrate upon stimulation with CXCL8 but not CCL2. J. Cell Biochem., 101: 135-146. DOI: $10.1002 /$ jcb.21172

Sasahara, M., A. Otani, A. Oishi, H. Kojima and N. Yoshimura et al., 2008. Activation of bone marrow-derived microglia promotes photoreceptor survival in inherited retinal degeneration. Am. J. Pathol. 172: 1693-1703.

DOI: 10.2353/ajpath.2008.080024

Sengupta, N., S. Caballero, R.N. Mames, A.M. Timmers and M. B. Grant et al., 2005. Preventing stem cell incorporation into choroidal neovascularization by targeting homing and attachment factors. Invest. Ophthalmol. Vis. Sci., 46: 343-348. DOI: 10.1167/iovs.04-0153

Sengupta, N., S. Caballero, R.N. Mames, J.M. Butler and M.B. Grant et al., 2003. The role of adult bone marrow-derived stem cells in choroidal neovascularisation. Invest. Ophthalmol. Vis. Sci., 44: 4908-4913. DOI: 10.1167/iovs.03-0342

Shi, M., J. Li, L. Liao, B. Chen and R.C. Zhao et al., 2007. Regulation of CXCR4 expression in human mesenchymal stem cells by cytokine treatment: Role in homing efficiency in NOD/SCID mice. Haematologica, 92: 897-904.

DOI: $10.3324 /$ haematol.10669 
Singh, M.S., P. Charbel Issa, R. Butler, C. Martin and R.E. MacLaren et al., 2013. Reversal of end-stage retinal degeneration and restoration of visual function by photoreceptor transplantation. Proc. Natl. Acad. Sci. USA, 110: 1101-1106. DOI: $10.1073 /$ pnas. 1119416110

Siqueira, 2012. Autologous bone marrow-derived stem cells transplantation for retinitis pigmentosa (RETICELL). ClinicalTrial.gov.

Siqueira, R.C., 2010. Autologous bone marrowderived stem cells transplantation for retinitis pigmentosa. ClinicalTrials.gov.

Siqueira, R.C., A. Messias, J.C. Voltarelli, I.U. Scott and R. Jorge, 2011. Intravitreal injection of autologous bone marrow-derived mononuclear cells for hereditary retinal dystrophy: A phase I trial. Retina, 31: 1207-1214. DOI: 10.1097/IAE.0b013e3181f9c242

Siqueira, R.C., A. Messias, J.C. Voltarelli, K. Messias and R.S. Arcieri et al., 2013. Resolution of macular oedema associated with retinitis pigmentosa after intravitreal use of autologous BM-derived hematopoietic stem cell transplantation. Bone Marrow Transplant., 48: 612-613. PMID: 23000646

Siqueria, 2011. Intravitreal bone marrow-derived stem cells in patients with advanced age-related macular degeneration (AMDCELL). ClinicalTrials.gov.

Takahashi, H., Y. Yanagi, Y. Tamaki, K. Muranaka and M. Sata et al., 2004. Contribution of bonemarrow-derived cells to choroidal neovascularisation. Biochem. Biophys. Res. Commun., 320: 372-375.

DOI: $10.1016 /$ j.bbrc.2004.05.177

Tejaswi, M., P.M. Vasanth, K. Suresh, T. Ramesh and R. Malothu, 2013. Design and evaluation of felodipine extended release tablets employing a new starch based polymer. Int. J. Biopharmaceut., 4: 27-33.

Thomson, J.A., J. Itskovitz-Eldor, S.S. Shapiro, M.A. Waknitz and J.M. Jones et al., 1998. Embryonic Stem Cell Lines Derived from Human Blastocysts. Science, 282: 1145-1147. DOI: $10.1126 /$ science.282.5391.1145

Tomita, M., H. Yamada, Y. Adachi, Y. Cui and S. Ikehara et al., 2004. Choroidal neovascularization is provided by bone marrow cells. Stem Cells, 22: 21-26. DOI: 10.1634/stemcells.22-1-21

Tse, W.T., J.D. Pendleton, W.M. Beyer, M.C. Egalka and E.C. Guinan, 2003. Suppression of allogeneic T-cell proliferation by human marrow stromal cells: Implications in transplantation. Transplantation, 75: 389-397.

DOI: 10.1097/01.TP.0000045055.63901.A9
Tsuruma, K., M. Yamauchi, S. Sugitani, T. Otsuka and H. Hara et al., 2014. Progranulin, a major secreted protein of mouse adipose-derived stem cells, inhibits light-induced retinal degeneration. Stem Cells Transl. Med., 3: 42-53.

DOI: $10.5966 /$ sctm.2013-0020

Tzameret, A., I. Sher, M. Belkin, A.J. Treves and Y. Rotenstreich et al., 2014. Transplantation of human bone marrow mesenchymal stem cells as a thin subretinal layer ameliorates retinal degeneration in a rat model of retinal dystrophy. Exp. Eye Res., 118: 135-144. DOI: 10.1016/j.exer.2013.10.023

UC, 2012. Clinical trial of autologous intravitreal bonemarrow CD34+ stem cells for retinopathy. ClinicalTrial.gov.

Uccelli, A., F. Benvenuto, A. Laroni and D. Giunti, 2011. Neuroprotective features of mesenchymal stem cells. Best Pract. Res. Clin. Haematol., 24: 59-64. DOI: 10.1016/j.beha.2011.01.004

Wang, H.C., J. Brown, H. Alayon and B.E. Stuck, 2010a. Transplantation of quantum dot-labelled bone marrow-derived stem cells into the vitreous of mice with laser-induced retinal injury: Survival, integration and differentiation. Vision Res., 50: 665-673. DOI: 10.1016/j.visres.2009.09.003

Wang, S., B. Lu, S. Girman, J. Duan and R. Lund et al., 2010b. Non-invasive stem cell therapy in a rat model for retinal degeneration and vascular pathology. PLoS One, 5: 9200-9200. DOI: 10.1371/journal.pone.0009200

Wu, Y., J. Wang, P.G. Scott and E.E. Tredget, 2007. Bone marrow-derived stem cells in wound healing: A review. Wound Repair Regenerat. Official Publicat. Wound Healing Society Eur. Tissue Repair Society, 15: 18-26. DOI: $10.1111 / \mathrm{j} .1524-475 X .2007 .00221 . \mathrm{x}$

$\mathrm{Xu}$, H., D.D. Sta Iglesia, J.L. Kielczewski, D.F. Valenta and H.A. Quigley et al., 2007. Characteristics of progenitor cells derived from adult ciliary body in mouse, rat and human eyes. Invest. Ophthalmol. Vis. Sci., 48: 1674-1682. DOI: $10.1167 /$ iovs.06-1034

Xu, Y.Q. and Z.C. Liu, 2008. Therapeutic potential of adult bone marrow stem cells in liver disease and delivery approaches. Stem Cell Rev., 4: 101-112. DOI: $10.1007 / \mathrm{s} 12015-008-9019-\mathrm{z}$

Yamanaka, S. and K. Takahashi, 2006. Induction of pluripotent stem cells from mouse embryonic and adult fibroblast cultures by defined factors. Cell, 126: 663-676. DOI: 10.1016/j.cell.2006.07.024

Yang, L.L., Q.J. Zhou, Y. Wang and Y.Q. Wang, 2010. Differentiation of human bone marrow-derived mesenchymal stem cells into neural-like cells by co-culture with retinal pigmented epithelial cells. Int. J. Ophthalmol., 3: 23-27. DOI: $10.3980 /$ j.issn.2222-3959.2010.01.06 
Yodoi, Y., M. Sasahara, T. Kameda, N. Yoshimura and A. Otani, 2007. Circulating hematopoietic stem cells in patients with neovascular age-related macular degeneration. Invest. Ophthalmol. Vis. Sci., 48: 5464-5472. DOI: $10.1167 /$ iovs.07-0093

Zhang, Y. and W. Wang, 2010. Effects of bone marrow mesenchymal stem cell transplantation on light-damaged retina. Invest. Ophthalmol. Vis. Sci., 51: 3742-3748. DOI: 10.1167/iovs.08-3314
Zhang, Z. and A.R. Alexanian, 2014. The neural plasticity of early-passage human bone marrowderived mesenchymal stem cells and their modulation with chromatin-modifying agents. J. Tissue Eng. Regen. Med., 8: 407-413.

DOI: $10.1002 /$ term 